\title{
Inferior vena cava thrombus after veno-arterial ECMO therapy treated with mechanical thrombectomy in an LVAD patient
}

\author{
Tomasz Urbanowicz' , Aleksander Araszkiewicz², Paweł Marcinkowski', Sylwia Sławek-Szmyt², \\ Bartłomiej Perek'1, Maciej Walczak', Marek Jemielity ${ }^{1}$
}

'Cardiac Surgery and Transplantology Department, Poznan University of Medical Sciences, Poznań, Poland

${ }^{2} 1^{\text {st }}$ Cardiology Department, Poznan University of Medical Sciences, Poznań, Poland

Correspondence to: Tomasz Urbanowicz, MD, PhD, Cardiac Surgery and Transplantology Department Poznan University of Medical Sciences,

Długa 1/2, 61-001 Poznań,

Poland,

phone: +48618549210

e-mail:

tomasz.urbanowicz@skpp.edu.pl

Copyright by the Author(s), 2022

DOI: 10.33963/KP.a2021.0083

Received:

July 8, 2021

Accepted:

August 6, 2021

Early publication date:

August 6, 2021
A 53-year-old male with dilated cardiomyopathy was admitted due to heart failure deterioration that progressed to a cardiogenic shock refractory to medical therapy and intra-aortic contrapulsation.

Peripheral veno-arterial extracorporeal membrane oxygenation ( $\mathrm{v}$-a ECMO) was applied. During ECMO therapy, the active clotting time ranged $160-220$ seconds, but the platelet count dropped from 244 to $2410^{9} /$ despite a negative result of testing for anti-PF4/Heparin antibodies.

The next day, left ventricular mechanical support (LVAD) (Heartmate 3, Abbott, Plymouth, MN, USA) implantation was performed through median sternotomy. Postoperatively, transthoracic echocardiography in the intensive care unit revealed a large, free-floating thrombus in the inferior vena cava (IVC)
(Figure 1A). Venous access was gained through the right femoral vein. Venography showed a large thrombus in the IVC (Supplementary material, Video S1). The Sentrant $20 \mathrm{~F}$ vascular sheath (Medtronic, Minneapolis, MN, USA) was inserted and subsequently, the Indigo 8F CAT XTRQ (Penumbra, Alameda, CA, USA) catheter was placed distally to the face of the clot. Aspiration was applied to the Indigo catheter via the Penumbra Engine until CAT8 became occluded. CAT8 was subsequently removed under continuous aspiration to ensure the clot remained engaged in the catheter tip and the $11 \mathrm{~cm}$ long thrombus (Figure 1B) was extracted out via a large-sized vascular sheath. No complications occurred from the procedure.

Thromboembolic complications [1] are the leading cause of morbidity in v-a ECMO that

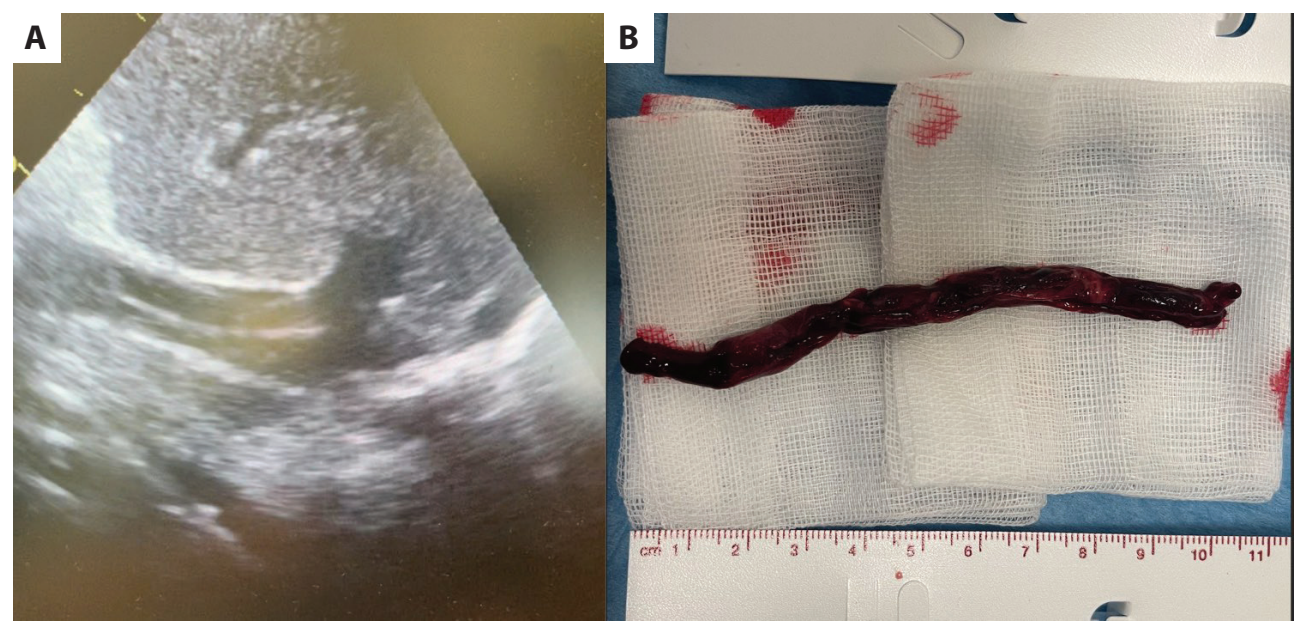

Figure 1. A. Tubular formation in the vena cava. B. Thrombus removed during thrombectomy 
is indicated in refractory cardiogenic shock [2] as a bridge to long-term LVAD.

We present the first, to our knowledge, description of successful removal of thrombus from the inferior vena cava, which occurred as a complication of ECMO therapy.

Most probably, the thrombus formed during ECMO therapy and the platelet count drop was an ominous indicator of this complication. It was found shortly after LVAD implantation as it migrated from the tip of the venous cannula after removal from the femoral vein. Alternative methods of thrombectomy were discussed since the surgical intervention was extremely risky.

Transcatheter thrombectomy with material aspiration in acute pulmonary embolism was found to be feasible and safe [3]. We applied an Indigo device inserted through a large-sized vascular sheath and used the XTRACT technique described in the PRISM trial in patients with peripheral arterial thromboembolism [4]. Our treatment was safe and effective. The therapy represents a viable and encouraging option in patients with "thrombus in-transit" in the IVC.

\section{Supplementary material}

Supplementary material is available at https://journals. viamedica.pl/kardiologia_polska.

\section{Article information}

Conflict of interest: None declared.

Open access: This article is available in open access under Creative Common Attribution-Non-Commercial-No Derivatives 4.0 International (CC BY-NC-ND 4.0) license, allowing to download articles and share them with others as long as they credit the authors and the publisher, but without permission to change them in any way or use them commercially. For commercial use, please contact the journal office at kardiologiapolska@ptkardio.pl.

\section{REFERENCES}

1. Murphy DA, Hockings LE, Andrews RK, et al. Extracorporeal membrane oxygenation-hemostatic complications. Transfus Med Rev. 2015; 29(2): 90-101, doi: 10.1016/j.tmrv.2014.12.001, indexed in Pubmed: 25595476.

2. Chakaramakkil MJ, Sivathasan C. ECMO and short-term support for cardiogenic shock in heart failure. Curr Cardiol Rep. 2018; 20(10): 87, doi: 10.1007/s11886-018-1041-4, indexed in Pubmed: 30116917.

3. Li K, Cui M, Zhang K, et al. Treatment of acute pulmonary embolism using rheolytic thrombectomy. Eurolntervention. 2021; 17(2): e158-e166, doi: 10.4244/EIJ-D-20-00259, indexed in Pubmed: 32863245.

4. Saxon RR, Benenati JF, Teigen C, et al. PRISM Trialists. Utility of a power aspiration-based extraction technique as an initial and secondary approach in the treatment of peripheral arterial thromboembolism: results of the multicenter PRISM trial. J Vasc Interv Radiol. 2018; 29(1): 92-100, doi: 10.1016/j.jvir.2017.08.019, indexed in Pubmed: 29128156. 